\title{
INNOVATIONS
}

\section{Creativity and the research process in academic libraries}

\author{
By Michael Engle \\ Reader Services Librarian \\ Linfield College
}

We don't often associate creativity with the work of librarians or librarianship. A look at $L i$ brary Literature shows that no subject headings containing the word "creative" are used to describe the work and writings of librarians. Yet bibliographic research is a creative process. Just as a writer searches the linguistic universe to bring a poem or novel into being, so the researcher searches the bibliographic universe to bring together the ideas and information in books and articles, joins them with personal experience and a particular vocabulary, and creates a unique product. Those of us who work with researchers have much to learn from the writings and experiences of the teachers who work with writers.

In a recent book, ${ }^{1}$ William Stafford writes and talks about his particular way of teaching writing and writing poetry. We are familiar with the idea that writing is a creative act; Stafford's book shows us that the teaching of writing can be a creative act too, part of a process entered into by the poet/ teacher and the students. The way the teacher enters into this process is all important to the integrity of the creator and of the creative product. Stafford's role as a teacher of creative writing is to participate in the process, rather than to channel it with positive and negative judgments, providing an opportunity for the writing which comes from the inner life of the student to grow.

The way we enter into the research process is equally important. If we understand research as a creative act, Stafford's approach to teaching writing begins to make sense as one approach to teaching research. Stafford encourages joint participa-

${ }^{1}$ William Stafford, You Must Revise Your Life (Ann Arbor: University of Michigan Press, 1986). tion in the creative process without imposing outer standards at the outset; the authority of a librarian who approaches teaching in this way comes from her ability to enter into the creative acts of the other researchers in the library - not as judge but as fellow traveler. By joining the researcher in the search process, librarians act as midwives for the creative process of others. Research becomes not only something that happens externally as a result of contact with the appropriate books, indexes and catalogs, but also something that comes from within the researcher. Stafford uses the image of two rivers flowing together to describe the way this inner and outer work intermingles and carries the creative process in the combined currents.

To experience this process, we must continually be performing our own research on topics of personal and professional interest to us and then creating something out of that research-a paper, a presentation, a new understanding. We can know something of the struggles of research for students by learning something entirely new, such as online searching, word processing, or public speaking. Taking a class in the college or university where we work can lead to a clearer understanding of the fear and marginality that are common to student researchers as they make the transition from high school and public libraries to effective use of an academic library. ${ }^{2} \mathrm{~A}$ thorough and continuing personal grounding in the experience of learning and research in an academic setting prepares us to join students and faculty in the creative act which bibliographic research can be. Listening to creative writing teachers and writers and reading their ac-

\footnotetext{
${ }^{2}$ Constance A. Mellon, "Library Anxiety: A Grounded Theory and Its Development," College of Research Libraries 47 (March 1986):160-65.
} 


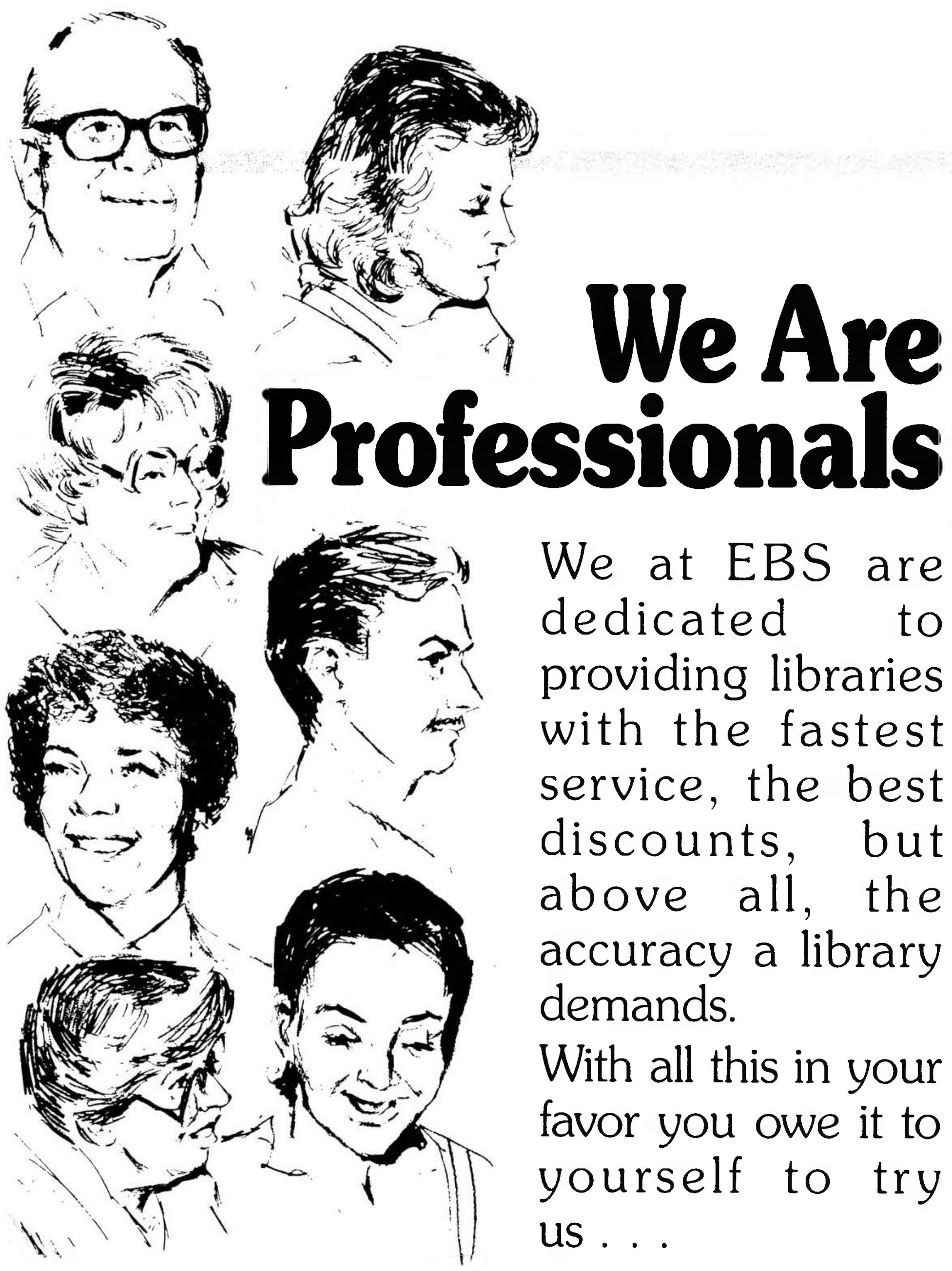

(IIIIIIII)IIII)

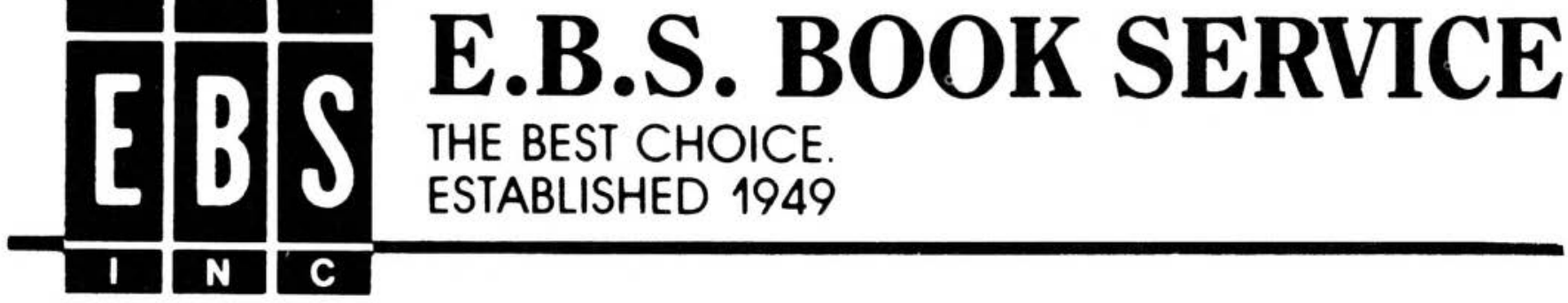

E.B.S. INC. BOOK SERVICE - 290 BROADWAY, LYNBROOK, NEW YORK 11563 - 516-593-1207 
counts of how they teach and how they write, we can begin to see our work as part of a creative process, making something new, original, never before seen or understood in that particular way.

Because a focus on process is central to both creative writing and creative research, we can each find help for our work when we hear and read writers on writing and teachers on teaching writing.
Stafford's particular approach may not be appropriate or helpful for everyone, but I believe all librarians working with researchers can find inspiration and help in the experiences of creative writers and teachers of creative writing. As the importance of creativity for librarians is recognized, we may even see some new and creative subject headings in Library Literature.

\title{
Managing innovation and innovators
}

\author{
By Fred M. Amram \\ Professor of Speech Communications, General College \\ University of Minnesota-Twin Cities
}

Lots of time and money are spent fostering creativity in the workplace. Witness ACRL President Joanne Euster's article, "Creativity, Innovation and Risk-Taking" in the Juily/August 1987 issue of $C \& R L$ News. Special efforts are made to help librarians, teachers, engineers, social workersmost employed persons-to invent new products and processes. We are told to "find a better way."

Much of the effort will be wasted, however, if the work environment in which employees find themselves is not conducive to new ideas and risktaking. No amount of employee skill and attitude development will enhance creativity unless the environment supports this effort.

Three key factors in the work environment have special influence on creativity: people, space, and time. While all three are interrelated, each will be discussed independently.

There are three categories of people in the environment who may enhance or inhibit creativitythe self, peers, and supervisors. The self is certainly the most severe critic. Who knows better which "put down" will be most effective? Who remembers best, consciously and subconsciously, the entire life history of failures? Training works best when it teaches the individual to try, to risk, to dare. Training works best when it demonstrates to the individual how one blocks creativity with unnecessary habits, fears, conformity, fixations, and all the other self-inhibitors. Innovation requires self-confidence-the "I think I can" attitudewhich comes largely from remembered success experiences.

Ultimately the motivation to risk (to want to try) requires feeling good about oneself and that comes from remembered success experiences. Good training and good management help people to feel successful and discover personal strengths.

A reward system that endorses effort as well as winners will help ensure success experiences. It is noteworthy that not every idea is a good idea, but without new ideas there is no innovation. Not every oyster contains a pearl.

Reward systems should allow for individual differences and preferences. Just as we each know our failures we also know best what makes us feel successful. But the encouragement of rewards may not be enough. A limited amount of pressure may bring out the best. "I expect you to be creative" says that I believe in you. Nothing enhances selfconfidence more than the confidence of others.

Other people in the work environment affect the individual's creativity as well as oneself. Peers surely have more influence on one's sense of creativity than bosses, and they provide a real opportunity to collaborate as well as a sense of our selfworth.

American culture is often not conducive to collaboration. We are a competitive people. In the academic as well as the corporate setting we are afraid that the other person may get the patent, the reward, the step up the elusive ladder to success. Again and again scholars report that they dare not share an idea until it's in "final form." Scientists report that they dare not ask advice-technical or procedural-for fear that an idea will slip away. And yet none of us is expert in all things. We need our colleagues to develop our ideas, to enhance our ideas, and to test our ideas. Consequently, American libraries must develop a collaboration system that encourages and teaches individuals to use one another's information, insights, and skills.

For one thing, libraries should develop group reward structures. If two or three individuals participated in an innovation, each should share in the reward-either equally or in proportion to their contribution. In some cases whole departments might be rewarded even though not all individuals contributed to the idea. Such group rewards recognize the importance of peers as emotional support 